\title{
UN LEKYTHOS DE FONDO BLANCO DEL PINTOR DE ÍCARO EN LA REAL ACADEMIA DE LA HISTORIA
}

\author{
MARTÍN ALMAGRO-GORBEA \\ Real Academia de la Historia
}

\begin{abstract}
La Real Academia de la Historia conserva un lekythos del pintor de ícaro decorado con una figura de Niké en libación funeraria datable entre los años 460 y 450 a. C. Forma parte de la colección Pascual de Gayangos.
\end{abstract}

We present a new lekythos by the Icarus Painter in the Royal History Academy at Madrid; the vase is decorated with a Niké in funerary libation and was made c. 460-450 BC. This piece is part of the Pascual de Gayangos antiquities collection.

La Real Academia de la Historia es una de las instituciones arqueológicas más antiguas de España, fundada por el rey Felipe $V$ en 1738 (Rumeu, 2002). Según explicita el artículo I de los Estatutos recogidos en la Real Cédula de 20 de Agosto de 1792, su tarea fundamental es el cultivo de la Historia, para purificar y limpiar la de nuestra España de las fábulas que la deslucen, e ilustrarla de las noticias que parezcan más provechosas (Anuario, 2002, p. XII). Desde el inicio de sus actividades, junto a sus diversos estudios, la Academia procedió a recoger epígrafes, monedas y otros objetos considerados como documentos históricos y con ellos fue formando un Gabinete de Antigüedades (AlmagroGorbea, 1999) para cuyo cuidado se creó el cargo de "Anticuario" ya en 1763 (Almagro-Gorbea, 1999,50 s. y 120 s.), colección de la que surgiría la idea de crear un Real Museo Español de Antigüedades, que acabaría por convertirse en el actual Museo Arqueológico Nacional (Almagro Gorbea y Maier, 1999; Marcos Pous, 1993).

En esta actividad llevada a cabo durante más de 250 años como principal centro de España dedicado al estudio de la Antigüedad (Almagro-Gorbea, 1999; Mora, 1998, 37 s.), la Academia fue formando una pequeña colección de antigüedades, muy variadas aunque no de gran importancia, si bien entre ellas existan algunas piezas destacadas, como el Disco de Teodosio (Almagro-Gorbea et alii, 1999).

La actual renovación de la Institución ha considerado como labor preferente la publica- ción de todas las colecciones, una vez inventariadas, fotografiadas y catalogadas en una base de datos, tarea iniciada en 1999. Este Catálogo del Gabinete de Antigüedades de la Real Academia de la Historia se ha abordado por medio de series paralelas que permiten incluir todas las muy variadas antigüedades recogidas en la Academia a lo largo del tiempo. La serie I se dedica a las Antigüedades, la II, a las Monedas y Medallas, la III, a las Esculturas, Cuadros y Grabados y la IV a la Documentación sobre Antigüedades.

Dentro de la serie I, además de los catálogos sobre Epigrafía $(\mathbf{I}, 1)$, se incluyen las diversas colecciones de Antigüedades Españolas $(I, 2)$ y de Antigüedades Extranjeras $(I, 3)$. Éstas están formadas por piezas del Antiguo Oriente, algunas Antigüedades Americanas y una pequeña colección de Antigüedades Clásicas, entre las que cabe señalar algo más de medio centenar de vasos griegos entre los que se encuentra el lekythos de fondo blanco al que se dedica esta nota'.

El lekythos, cuyo $N^{\circ}$ de Inventario es el 824, procede de la Colección Pascual Gayangos y Arce, donada a la Real Academia de la Historia en 1898 por sus hijos, Dña. Emilia de

Conste nuestro agradecimiento al Deutsches Archeologisches Institut, de Berlín, por su generosa hospitalidad y las facilidades dadas para el acceso a su Biblioteca, gracias a lo que ha sido posible llevar a cabo el estudio de esta pieza, hasta ahora prácticamente inédita. 


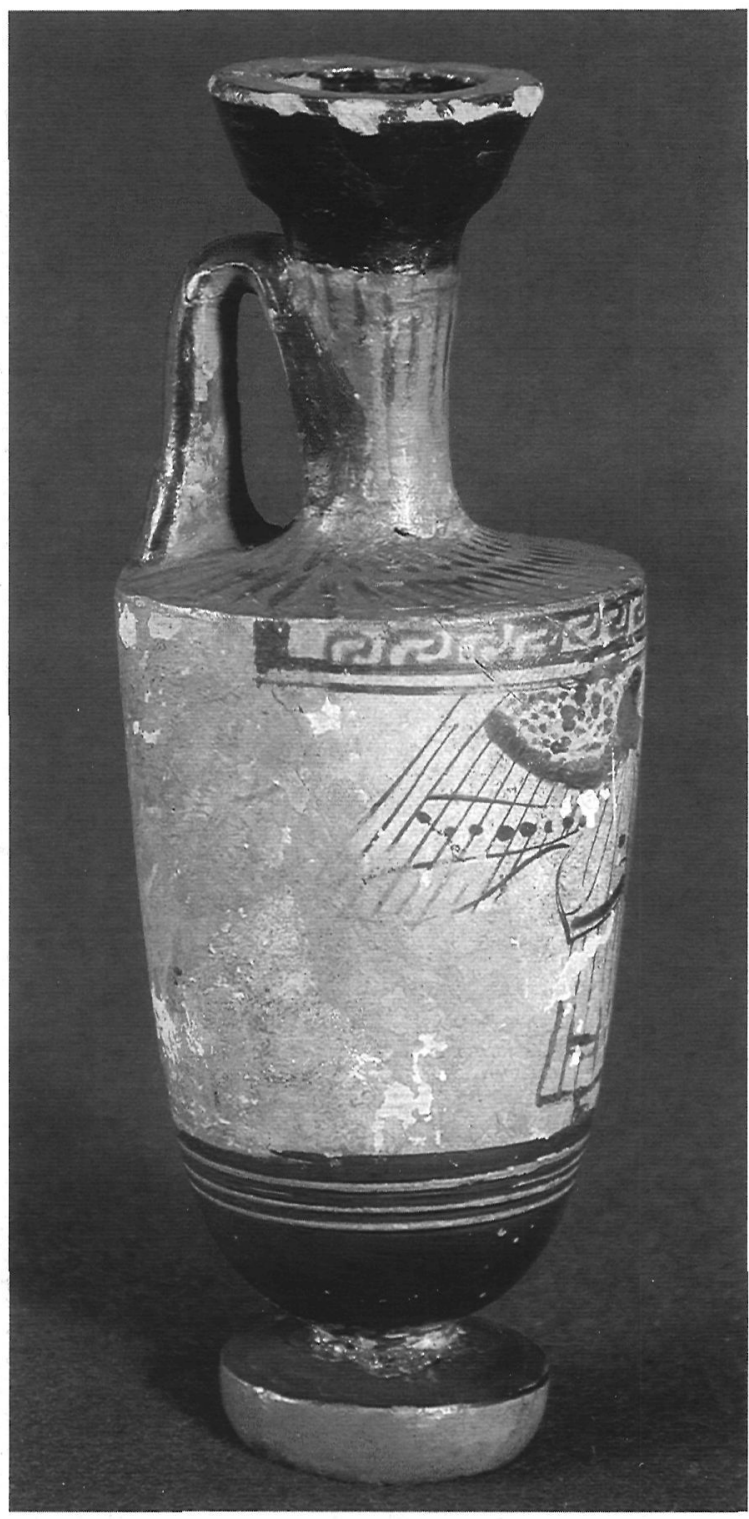

Figura 1: Lekythos del Pintor de Ícaro de la Real Academia de la Historia. Lado derecho.

Gayangos de Riaño y D. José de Gayangos ${ }^{2}$, tal como indica el antiguo Inventario de 1903 (García López, 1903, 118, nº inv. 824), sin que exista más información sobre su origen ni sobre cómo llegó a manos de su anterior propietario, Pascual de Gayangos. Este personaje, nacido en Sevilla en 1809, es uno de los "anticuarios" españoles más destacados e interesantes del siglo XIX (Roca, 1897, 544 s.). Académico de la Real Academia de la Historia y Catedrático de Árabe de la Universidad Central, fue un hombre culto y viajero y como buen especialista en lenguas orientales puede considerarse el maestro de numerosos arabistas españoles de la segunda mitad del siglo XIX. Estaba particularmente relacionado con Inglaterra, pues se había casado en 1828 con una inglesa en Londres, ciudad en la que volvió a vivir diversas veces a lo largo de su larga vida, en especial entre 1837 a 1843, estancia durante la que se dedicó a clasificar las antigüedades y manuscritos españoles del British Museum, pero también volvió a residir en esa ciudad desde 1895 hasta su muerte, ocurrida en 1897 (Roca, 1897, 545, n. 2; id. 1898, 13 s. y $70 \mathrm{~s}$.).

Aunque no se conserva documentación alguna de cómo llegó a manos de Gayangos este lekythos, dada su afición por coleccionar manuscritos árabes y antigüedades mantenida hasta los últimos años de su vida, cabe suponer que debió de adquirir esta pieza en Londres, probablemente procedente de Grecia o del Sur de Italia. En todo caso, lo que sí es seguro es que formó parte de la Colección Gayangos hasta su donación a la Real Academia de la Historia por sus hijos en 1897 (Fita y Rodríguez Villa, 1898, 93; García y López, 1913, 126; Roca, 1898, 116), por lo que es uno de los raros vasos griegos llegados a colecciones españolas en el siglo XIX, lo que añade interés historiográfico al que de por sí pueda ofrecer este pequeño vaso conservado en el Gabinete de Antigüedades de la Real Academia de la Historia.

\section{DESCRIPCIÓN}

Forma y pasta: Pequeño lekythos de cuerpo cilíndrico con la parte inferior redondeada y un marcado ángulo que separa el cuerpo cilíndrico del hombro levemente inclinado del vaso (Fig. 1 y 2). Ofrece un alto cuello cilíndrico que en su parte superior se abre con una boca caliciforme a modo de una gran moldura troncocónica, de perfil ligeramente convexo y con un labio ancho y plano. De debajo de la moldura de la boca parte una asa en forma de cinta de sección ovalada que llega hasta el ángulo en el que finaliza el hombro. El vaso se apoya sobre un pie cilíndrico, de perfil ligeramente convexo y con la superficie superior ligeramente inclinada hacia el exterior, que queda unido al cuerpo por medio de un pequeño baquetón. Estas características permiten considerarlo como una forma secundaria de tipo

\footnotetext{
2 Sobre esta donación a la Real Academia de la Historia sólo consta que fue realizada por sus hijos, Emilia Gayangos de Riaño y José de Gayangos, en 1898. Fita y Rodríguez Villa, 1898, 93; Almagro-Gorbea y Maier, 2001, 194 y 198.
} 


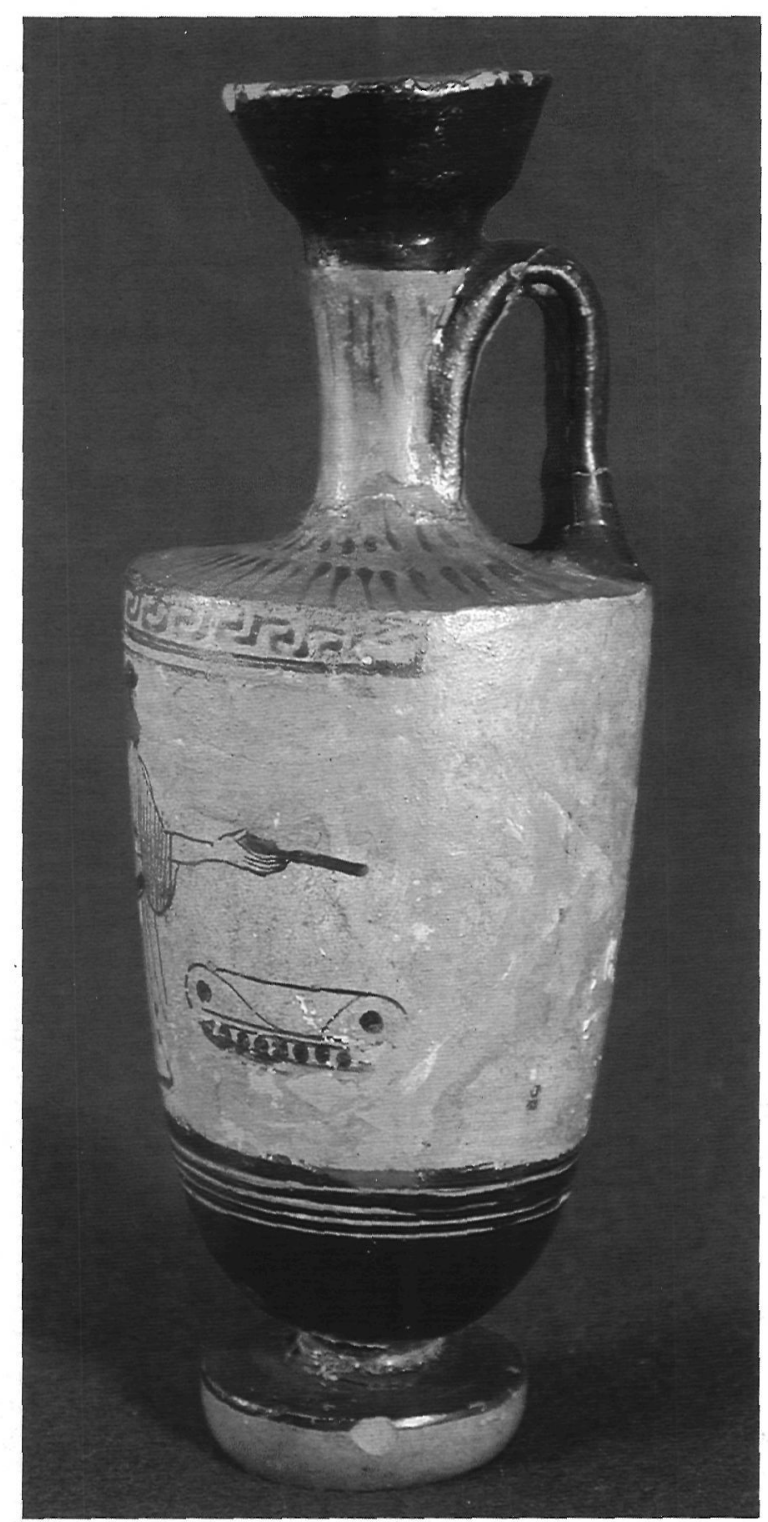

Figura 2: Lekythos del Pintor de Ícaro de la Real Academia de la Historia. Lado izquierdo.

PL (Beazley, 1963, 675; Kurtz, 1975, 81 s.) a pesar de su relativa esbeltez. Estos lekythoi se caracterizan por su tamaño relativamente pequeño, su boca corta de lados rectos, el cuello largo sin barniz, el hombro casi plano y el cuerpo acabado en un pie discoidal simple.

Toda la boca, el exterior del asa, la parte inferior del cuerpo y la superior del pie están pintadas de barniz, mientras que el cuello, el interior del asa, el hombro y la parte lateral e inferior del pie están reservadas, lo mismo que toda la zona superior del cuerpo, que aparece cubierta del característico "fondo blanco" para recibir encima la escena pintada.

El hombro se ha decorado con dos series de lengüetas pintadas con pequeños trazos de barniz (Fig. 2). Las de la serie superior, más cortas, representan ovas muy estilizadas y la inferior, capullos de lotos muy degenerados. Para enmarcar la escena pintada sobre el característico fondo blanco de estos vasos, en la parte superior se ha trazado una cenefa formada por una línea de meandros entre una línea horizontal en el ángulo del hombro y otras dos casi juntas en la parte inferior, mientras que el límite inferior lo constituye una banda formada por una línea horizontal gruesa sobre tres líneas finas. Las figuras están pintadas con líneas de contorno en relieve, algo más suaves en las interiores, pero también ofrece algunos gruesos trazos de pintura desvaída para señalar detalles decorativos, como los bordes del himation o los plumones de las alas.

Iconografía: La escena principal la constituye una figura femenina alada, Niké, representada de pie y de perfil hacia la derecha (Fig. 3). Con su mano derecha sostiene, sobre un altar situado frente a ella, un objeto, representado por una simple línea gruesa de barniz diluido, que cabe interpretar como una pátera para hacer una libación, iconografía muy frecuente en este tipo de vasos.

La figura de Niké viste un chiton con amplias mangas. La derecha, a pesar del esquematismo del dibujo, se ha representado cayendo con pliegues dibujados por medio de 8 finas líneas paralelas casi verticales, estando señalado su contorno por una línea más

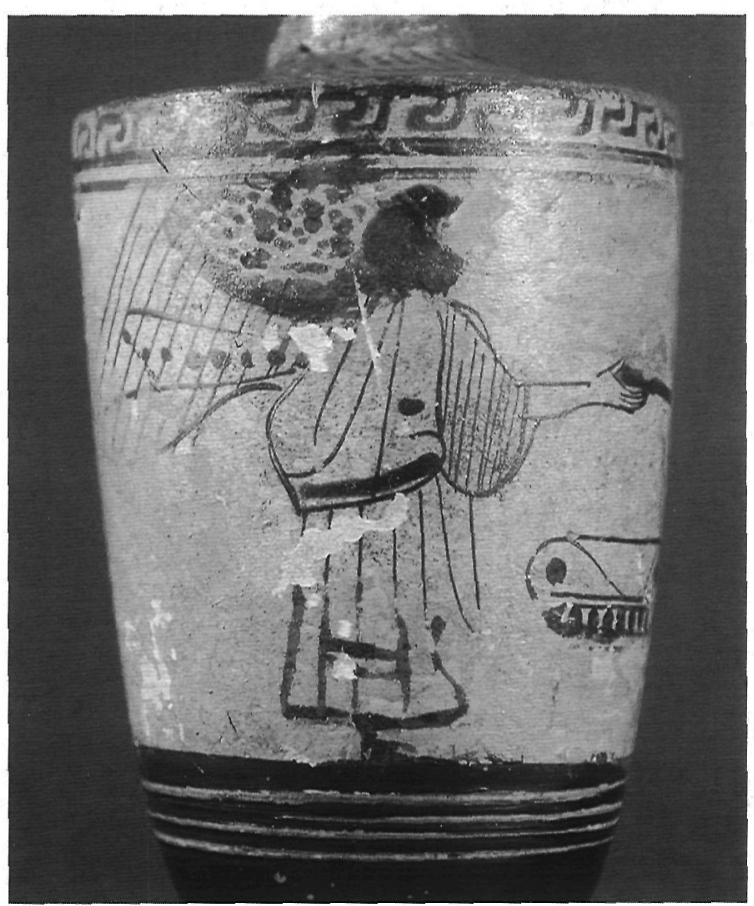

Figura 3: Lekythos del Pintor de Ícaro de la Real Academia de la Historia. Figura de Nike ante un altar. 


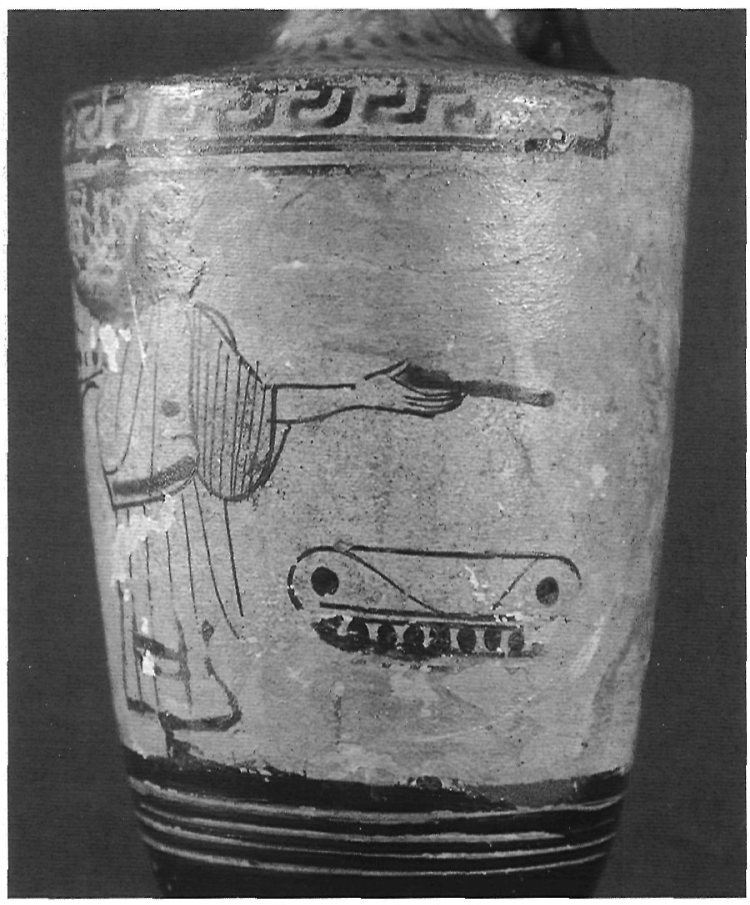

Figura 4: Lekythos del Pintor de Ícaro de la Real Academia de la Historia. Detalle del altar.

gruesa y de mayor relieve, que en la parte superior casi coincide con la línea superior del brazo. Encima del chiton lleva un himation, cuya parte superior está igualmente trazada con una línea más gruesa en su contorno y con tres líneas finas en su interior para representar los pliegues, además de una gruesa banda de barniz ligeramente diluido y un punto que representan la decoración del borde del himation, sumamente esquematizada. Por debajo del himation se ha dibujado la parte inferior del chiton, a base de siete líneas casi verticales cuyo extremo inferior desaparece bajo repintes modernos. De la cabeza de la Niké sólo se conserva la parte posterior, pero permite apreciar que estaba pintada con el cabello al aire representado por una mancha de barniz ligeramente saliente a la altura del flequillo. Por detrás del himation se ha dibujado el ala entre el borde superior del campo decorativo y una línea curva sinuosa que marca su contorno, a base de una parte superior con puntos negros, que representan los plumones, y doce líneas casi verticales y paralelas que representan las plumas, quedando ambas zonas separadas por una gruesa pincelada, mientras que otras dos finas con ocho gruesos puntos intermedios aluden a la estructura del plumaje.

La Niké avanza su brazo derecho sobre el altar, habiéndose dibujado la línea superior del brazo bajo el chiton, las dos del antebrazo y la mano con todos los dedos, pues se aprecia incluso el pulgar hacia arriba para sujetar mejor la pátera con la que está haciendo la libación, representada por una simple línea gruesa. El altar (Fig. 4) está formado por un cuadrado pintado con líneas suaves que se alza sobre una plataforma rectangular de la que casi no quedan trazas, pero sí se aprecia la coronación formada por dos volutas representadas por sendas formas ovoides con un punto en su centro que aluden a las volutas, mientras que la moldura de la cornisa se ha pintado a base de tres líneas paralelas que, entre las dos inferiores, muestran diez gruesos puntos que representan los dentones.

Dimensiones: Altura: $11,6 \mathrm{~cm}$; Diámetro: 4,4 $\mathrm{cm}$; Grosor de las paredes: $0.5 \mathrm{~cm}$; Altura del cuello: $4 \mathrm{~cm}$; Altura de la boca: $1,2 \mathrm{~cm}$; Diámetro de la boca: $3 \mathrm{~cm}$; Altura del pie: $0,7 \mathrm{~cm}$; Diámetro del pié: $2,8 \mathrm{~cm}$.

Conservación: El vaso está aparentemente completo, pero ha sido muy restaurado en el siglo XIX y ofrece amplias zonas repintadas, seguramente para tapar partes que faltaban o que habían perdido la pintura original, en especial en la parte inferior de la figura de Niké y en toda la parte posterior del campo decorativo situado bajo el asa.

\section{PARALELOS}

Este lekythos se incluye, por su forma y su decoración, entre los conocidos como de "fondo blanco" (Fairbanks, 1907 y 1914; Haspels, 1936; Beazley, 1938; Kurtz, 1975). Su forma, como ya se ha indicado, es de tipo PL (Beazley, 1963, 675; Kurtz, 1975, 81 s.), denominación dada por el ejemplar del Petit Palais 336 (Plaoutine, 1941, lám. 23,1-4). Esta forma fue usada por el Grupo formado por el Pintor de Ícaro y el de las Sirenas o Seireniske Peinter (Beazley, 1963, 696 s), pero este lekythos de la Real Academia de la Historia, RAH 824, ofrece una forma que resulta algo más esbelta y tampoco los trazos que decoran el hombro son propios de los lekythoi de tipo PL, sino de los pequeños lekythoi de fondo blanco de forma ATL (CVA Getty Museum 7 [USA 32], lám. 381,3-4), parecida a la anterior pero más esbelta, que utilizaron, sobretodo, el Pintor de Aischines y el de Tymbos.

La figura de Niké de este lekythos RAH 824 resulta característica de los lekythoi de fondo blanco de pequeño tamaño en los decenios centrales del siglo V a.C.( Goulaki-Voutira, 
$1992, n^{\circ} 94$ s.), en los que es evidente que esta figura se generalizó como una alusión al culto funerario y a la heroización del difunto ${ }^{3}$. La forma de sus alas sigue los modelos habituales hacia el 475 a.C., como los del Pintor de Carlsruhe y la decoración de las partes bajas del himation con trazos gruesos es igualmente un recurso que se generaliza hacia los años 480-470 a.C. (Chase-Pease 1942, lám. 58,2), lo mismo que la composición de la escena, como puede verse, como ejemplo, en piezas del Pintor de Berlín (Beazley, 1974, n 31; IslerKerényi, 1971, 27 s., lám. 6-10; Kurtz, 1983, lám. 4,10$)$ y lo mismo cabe decir del empleo de una gruesa línea para separar la parte superior del ala de la inferior ${ }^{4}$. Estos recursos, cada vez más amanerados, prosiguen hasta mediados de siglo y ayudan a comprender el dibujo, ya muy estilizado y adocenado, del lekythos RAH 824, cuya figura de Niké dirigiéndose hacia un altar para hacer una libación es una copia adocenada de la que ofrecen lekythoi como los del Pintor de Bowdoin (GoulakiVoutira, 1992, lám. 569, n 108).

Las características estilísticas y la composición de la escena permiten relacionar el lekythos RAH 824 con algunos lekythoi de fondo blanco de mediados del siglo $V$ a.C. atribuidos al "Pintor de Ícaro". Este pintor debió gozar de larga vida, pues su producción se extiende durante más de 25 años, ya que en sus inicios presenta características todavía severas, mientras que parte de su obra fue inicialmente atribuida por Beazley a un "Pintor de Palermo 1191", que posteriormente dicho autor consideró que representa las obras tardías del Pintor de Ícaro (Beazley, 1963, 696), pues el estilo severo ha desaparecido por completo en sus últimas creaciones, ya de mediados del siglo $\mathrm{V}$ a.C. De su producción, que debió alcanzar varios miles de piezas salidas de sus manos, actualmente se han identificado más de 100 vasos (Beazley, 1963, 696 s. y 16661667; id., 1971, 407-408; Burn y Glynn, 1982, 137-138), pero su extensa obra todavía es mal conocida, pues raramente han sido ordenadas las obras de estos artesanos menores (Hemelrijk, 1976, 93-95).

Entre las piezas más similares al lekythos RAH 824 cabe señalar uno de la Colección Vlasto de Atenas, que ya fue atribuido al Pintor de Ícaro por Haspels (Haspels, 1936, 271, lám. 54,5 ; Beazley, $\left.1963,699, n^{\circ} 65\right)$ y que aparece decorado con una Niké hacia la derecha con una corona en la mano (Fig. 7.7). Aunque la forma es menos esbelta y la decoración acce- soria es más compleja que este lekythos de Madrid, la estructura de la Niké es idéntica en su forma y actitud en ambos casos, con el mismo pelo sobre la frente, la manga del chiton saliendo del himation con los mismos pliegues a base de líneas verticales finas, el himation con una pincelada gruesa para la banda del borde $y$ varias verticales para indicar los pliegues; además ofrece igual estructura del ala con los mismos puntos en la zona superior y la misma división del plumaje a base de trazos verticales y horizontales finos, etc. Pero la calidad del lekythos de la colección Vlasto es algo mejor, pues aunque ambos ofrecen tamaños parecidos y la misma y característica cenefa de meandros entre dos líneas en la parte superior de la escena, la pieza RAH 824 muestra una factura más descuidada y tosca, propia de las obras tardías de este pintor, como se puede apreciar en la decoración complementaria mucho más rica del lekythos de la Colección Vlasto, con el cuello decorado a base de meandros, zig-zag exentos y trazos, el hombro con palmetas contrapuestas y la cenefa que limita la parte inferior de la decoración es un zig-zag, frente a los simples trazos transversales en el hombro, a modo de lengüetas o lotos muy estilizados, y la línea gruesa y tres finas en la parte inferior del campo decorativo del lekythos RAH 824. Todavia resulta más próxima a esta última pieza la Niké de un lekythos de proporción algo más esbelta del Museo de Copenhaghe (Blinkenberg y Friis Johansen 1929, lám. 170,3) (Fig. 7.10), igualmente atribuido al Pintor de Ícaro por Beazley (Beazley, 1963, 699, $\left.n^{\circ} 67\right)$. Sus cenefas superior e inferior son muy similares, así como la estructura del ala y del vestido de Niké y la forma del altar, con las mismas fórmulas a base de puntos para representar las volutas laterales y los dentículos de la cornisa. Incluso esta figura de Niké demuestra cómo el punto que ofrece el himation en el lekythos de Madrid es la esquematización del trazo corto horizontal del borde plegado del mismo, por lo que la pieza de Madrid parece una versión más degenerada de este modelo iconográfico de Niké del Pintor de ícaro.

Características semejantes a las que ofrece el lekythos RAH 824 aparecen en otras obras atribuidas al Pintor de ícaro, como la for-

\footnotetext{
3 The Ernest Brummer Collection, Ancient Art II, (Auction Sale 1979), Zurich, 340-341, n 702; Götte, 1957, 39 s.; IslerKerényi, 1971, 30-31; Goulaki-Voutira, 1992, 898.

4 Blinkenberg y Friis Johansen 1928, lám. 144,2, que se publica fechado entre el 475 y el 450 a.C.
} 


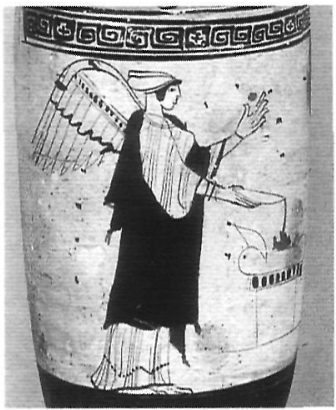

1

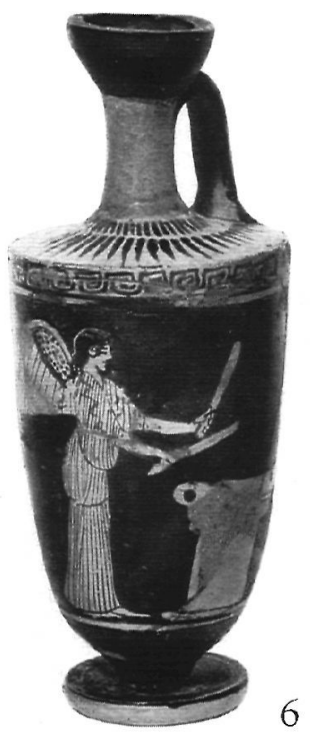

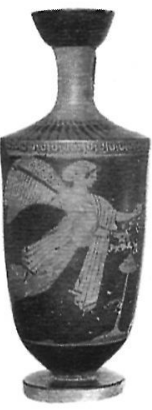

2

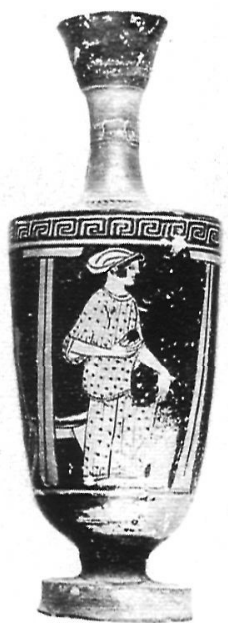

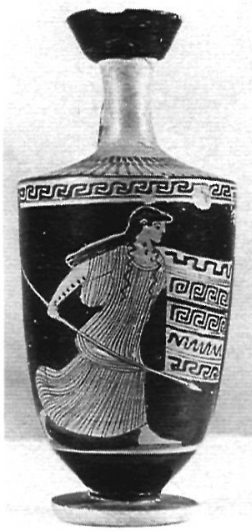

3

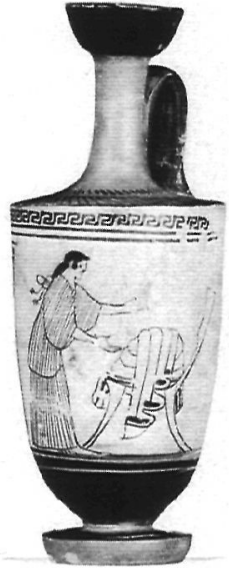

4

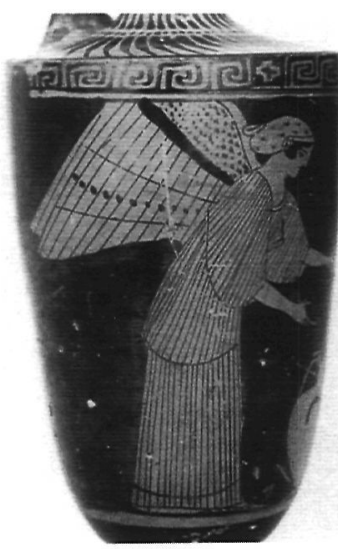

5

Figura 5: 1: Lekythos con Niké ante un altar del Pintor de Bowdoin ( LIMCVI,2, $\mathrm{n}^{\circ}$ 108); 2:Lekythos de la Colección Goluchow (CVA, Polonia 1, lám. 23,1); 3: Lekythos del Museo del Louvre L 52; 4: Lekythos de Tübingen (CVA 5, Deutschland 54); 5: Lekythos de Ámsterdam APM 2838; 6: Lekythos del Museo de Villa Giulia n 50582; 7: Lekythos del Museo Nacional de Atenas n 18572; 8: Oinochoe de la Colección Vlasto; 9: Lekythos de Nueva York 249737.

ma del peinado con su característico flequillo - la manera de representar la mano con los dedos, la amplia manga caída del chiton, los trazos gruesos para marcar el borde decorado del himation, que vemos en una pieza de Tübingen (Burow 1986, lám. 26,1-2) (Fig. 5.4), el flequillo y la base del campo decorativo con líneas en otra pieza de esa colección (Burow 1986, lám. 26,2-4) (Fig. 6.5), etc. Además, es interesante observar que las piezas que muestran una forma PL semejantes a las del RAH 824 son las que ofrecen características de dibujo más suelto y, probablemente, más avanzado, lo que parece indicar una preferencia por esta forma en la producción tardía de este pintor, que parece coincidir con los vasos de menor tamaño y dibujo más amanerado.
Hemelrijk (1976) hace años observó cómo dentro de los numerosos vasos atribuidos al Pintor de Ícaro se aprecia una clara evolución, que ejemplificó en 6 piezas, que pueden considerarse representativas de otras tantas fases en la obra de este pintor: 1, Amsterdam APM 2838 (Fig. 5.5); 2, Amsterdam APM B 8735 (Fig. 6.4); 3, Atenas NM 18877 (Fig. 6.9); 4, Vente $X$ de Bâle, lám. 20, no 417; 5, Dresden ZV 2025 (Fig. 7.5); 6, Copenaghe NM 167 (Fig. 7.11).

Si se prosigue la clasificación de la obra del Pintor de Ícaro en esa acertada línea de análisis, a pesar del riesgo que implica una ordenación cronológica basada exclusivamente en criterios estilisticos en los que también han podido influir factores como el tamaño del vaso 

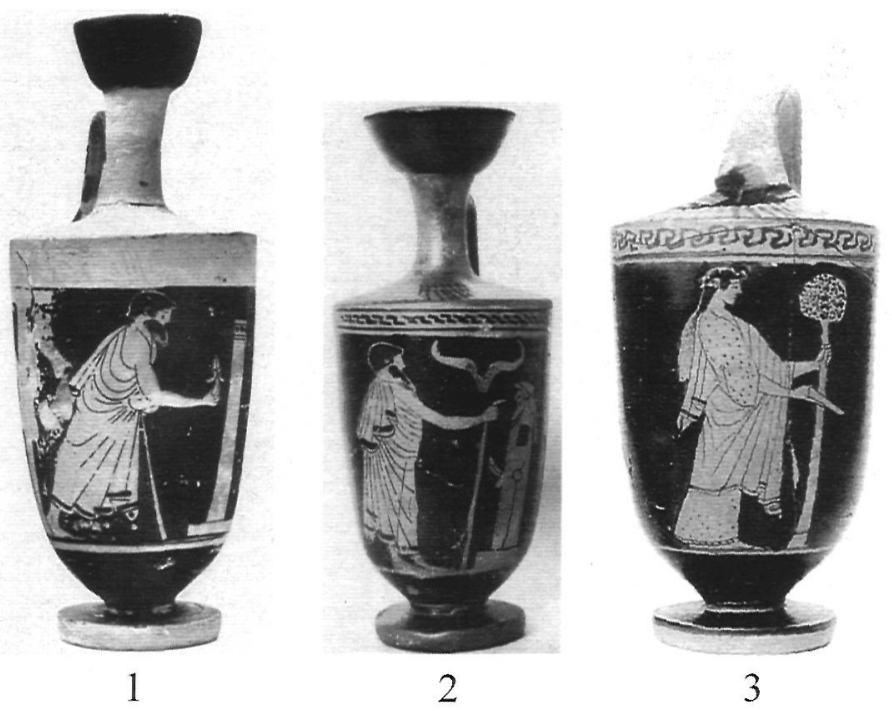
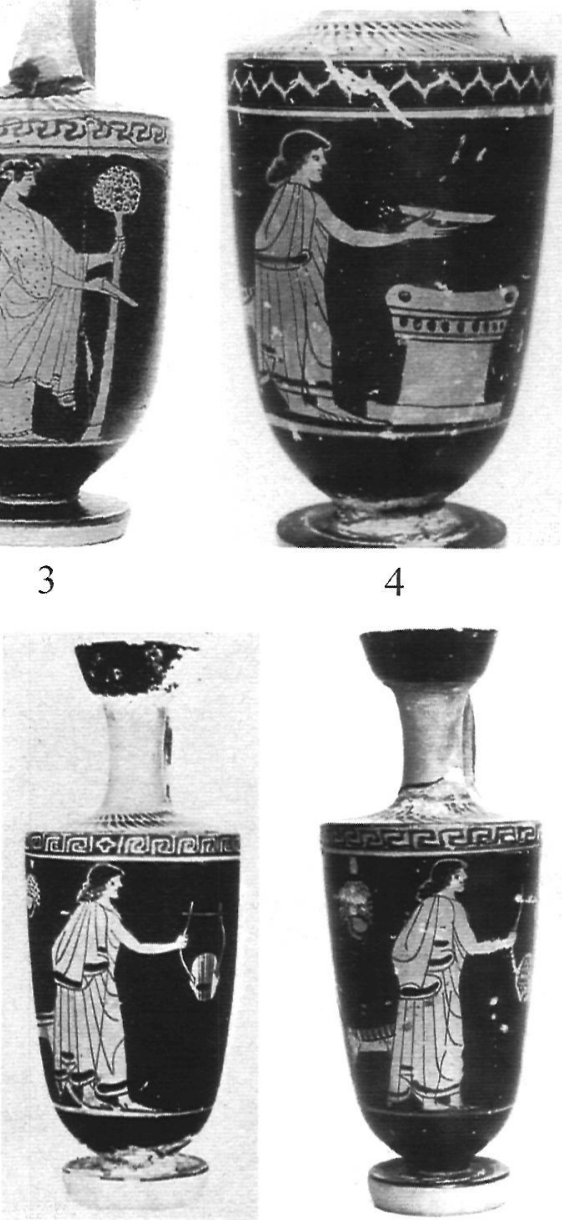

8
4

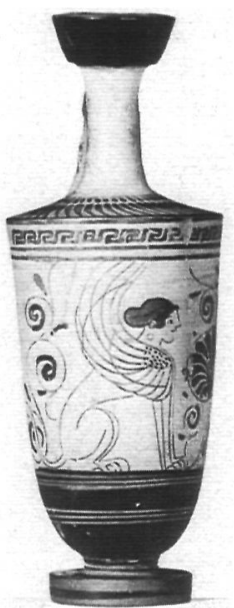

5

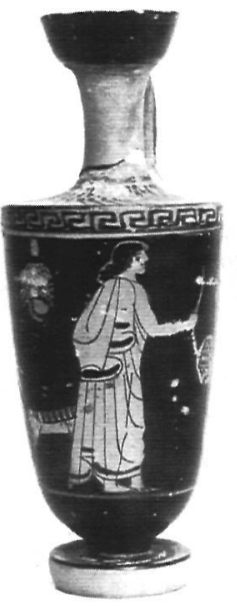

9

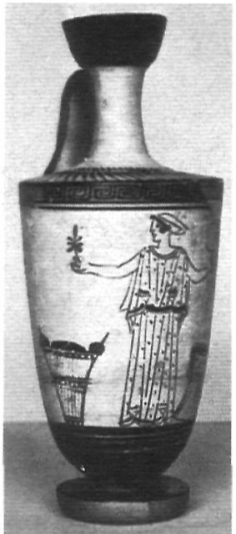

10

Figura 6: 1: Lekythos de Atenas MN 11.393; 2: Lekythos de Hamburgo; 3: Lekythos del Ágora de Atenas $n^{\circ} \mathrm{P} 17601 ; 4$ : Lekythos de Ámsterdam APM B 8735 (según Hemelrijk, 1976); 5: Lekythos de Tübingen (CVA 5, Deutschland 54, lám. 26,34); 6: Oinochoe del Ashmoleam Museum 1927.4467; 7: Lekythos del Museo de Palermo 798; 8: Lekythos del Museo de Palermo 31; 9: Lekythos del Museo Nacional de Atenas $n^{\circ}$ 18877; 10: Lekythos de fondo blanco del Museo de Palermo 177.

y el mayor o menor cuidado puesto en la decoración de una determinada pieza, es posible situar con precisión el lugar que corresponde al lekythos RAH 824 dentro de la amplia producción de dicho artesano.

Hemelrijk consideró en primer lugar el lekythos de Ámsterdam APM 2838, ciertamente una de sus mejores piezas, todavía de tradición severa de hacia el 470 a.C. (Hemelrijk, 1976, fig. 1-4). Aunque próximos a esta pieza, deben considerarse anteriores el lekythos de la colección Goluchow (Bulas 1931, lám. 23,1) (Fig. 5.2), el de Paris L 52 (Zimmermann, 1980, 174, fig. 9) (Fig. 5.3) y el citado de Tübingen (Burow 1986, lám. 26,1-2) (Fig. 5.4), mientras que con el citado de Amsterdam APM 2838 (Fig. 5.5) se situaría el de Villa Giulia 50582
(Bartoccini y de Agostino, 1961, lám. 43), ya menos cuidado (Fig. 5.6), y a este grupo hay que añadir el de Atenas 18572 (Courbin, 1954, 98, fig. 2) (Fig. 5.7) y el oinochoe de la Colección Vlasto (Papaspyridi, 1945, 42, lám. 4b) (Fig. 5.8), de idéntica decoración que el lekythos de Nueva York $249737^{5}$ (Fig. 5.9) que ha dado nombre al pintor.

A continuación, se pueden colocar los lekythoi de Atenas MN 11.393 (Karouzou, 1962, 451, fig. 14) (Fig. 6.1), el de Hamburgo (Mercklin, 1935, 76 s., fig. 13) (Fig. 6.2) y el del Ágora de Atenas P17601 (Thompson, 1948,

\footnotetext{
5 Beazley, 1963, n 1; A. de Franciscis, "Icaro", Enciclopedia dell'Arte Antica 4, 83, fig. 107.
} 
188, lám. 67,3; Beazley, 1963, nº 47) (Fig. 6.3), tras los cuales iría el lekythos de Ámsterdam APM B 8735 (Fig. 6.4), que Hemelrijk consideró representativo de un segundo grupo (Hemelrijk, 1976, fig. 5-8). Ya con este lekythos de Ámsterdam APM B 8735 iría otro de Tübingen (Burow 1986, lám. 26,3-4) (Fig. 6.5), el oinochoe del Ashmoleam $1927.4467^{6}$ (Fig. 6.6) y, probablemente, el lekythos de Palermo 798 (La Genière 1971, lám. 4,1) (Fig. 6.7), decorado con la misma escena que el de Bucarest 0467 (Dimitriu y Alexandrescu 1965, lám. 33,7 y 34,1 ) (Fig. 7.6), pero claramente anterior a éste último. Este grupo evidencia un claro avance estilístico, que permitiría colocar las obras correspondientes al mismo hacia el decenio 470-460 a.C.

En la fase 3 del Pintor de Ícaro según Hemelrijk se sitúa el de Palermo 31 (La Genière 1971, lám. 1,1-2) (Fig. 6.8), por ser prácticamente idéntico aunque algo anterior al lekythos de Atenas NM 18877 (Hemelrijk, 1976, fig. 9) (Fig. 6.9), que constituiria la referencia, siendo probablemente ambos todavía anteriores al 460 a.C. No lejos debe quedar el lekythos de Palermo 177 de fondo blanco La Genière 1971, lám. 5,1-2) (Fig. 6.10), con la misma representación que Copenhague NM 137 (Blinkenberg y Friis Johansen 1931, lam. 165,7, $n^{\circ}$ inv. VIII, 68) (Fig. 7.1), pero más cuidada y algo anterior. A su vez, este lekythos de Copenhague tiene la misma cara que la Niké de Nápoles MN 3216 (Goulaki-Voutira, 1992, lám. 570, n 110) (Fig. 7.2), siendo todos posteriores al de Atenas NM 18877 que constituía la pieza de referencia para esta fase 3 . También hacia esta fase se podría tal vez colocar el lekythos con una lechuza de Frankfort (Schaal, 1923, lám. 21c) (Fig. 7.3), a juzgar por sus alas todavía cuidadas, y el atribuido a la manera del Pintor de Ícaro (Beazley, 1963, 701) de Leipzig T 429 (Hauser, 1896, 192, fig. 36) (Fig. 7.4), con una forma del vaso idéntica, aunque algo menos esbelta, que el de la RAH 824 (Fig. 1 y 2), ya que también ofrece dos líneas bajo la greca superior y 5 o 6 delimitando la escena por debajo, lo que evidencia que se trata de una obra del mismo taller $y$, muy posiblemente, de la misma mano.

Las últimas piezas documentadas del Pintor de Ícaro ya evidencian una producción más tardía y cada vez más amanerada. Hemelrijk $(1976,95)$ coloca a continuación un vaso del mercado de antigüedades de clasificación discutida por el propio Beazley (Beazley, 1963, n 50; Vente X de Bâle, 1951, lám. 20, nº
417) y, tras esta pieza, se podría colocar el lekythos de Dresden ZV 2025 (Müller, 1925, 122, fig. 20) (Fig. 7.5) y el de Bucarest 0467 (Dimitriu y Alexandrescu 1965, lám. 34,1) (Fig. 7.6), éste claramente posterior al de Palermo 798 (Fig. 6.7), por lo que estas piezas ya se deben fechar probablemente dentro del decenio 460-450 a.C.

Finalmente, hay un conjunto de obras del Pintor de Ícaro que ofrecen una calidad cada vez peor, lo que sólo en parte puede explicarse por el pequeño tamaño de las piezas, entre 11 y $12 \mathrm{~cm}$, ya que también evidencia una producción cada vez más seriada, descuidada y amanerada. Esta última serie la iniciaría el lekythos ya citado de la Colección Vlasto (Haspels, 1936, lám. 54,5) (Fig. 7.7), probablemente el más antiguo de esta fase. A continuación iria el de Nápoles procedente de Cumas decorado con una sirena (Gabrici, 1913, lám. 84,2; Beazley, 1963, $n^{\circ}$ 55) (Fig. 7.8) y el de Nauplia $^{7}$ (Fig. 7.9), ambos muy semejantes. Próximo a ellos queda el de la RAH 824, que también es pequeño y cuya Niké tiene el ala muy parecida a los anteriores (Fig. 3). Por último, el lekythos VIII-30 de Copenhague con una Niké ante el altar (Blinkenberg y Friis Johansen 1929, lam. 170,3) (Fig. 7.10) es de estilo aún más descuidado. Todas estas piezas ya se deben fechar no lejos del 450 a.C.

Sin embargo, todavía parecen posteriores las últimas producciones conocidas del Pintor de Ícaro, como el lekythos con una sirena de Copenhague NM 167 (Hemelrijk, 1976, fig. 12; Blinkenberg - Friis Johansen 1931, lam. 165,10) (Fig. 7.11) y el oinochoe con un cisne tirando de un carro de Cambridge (Lamb 1936, lám. 26,5) (Fig. 7.12), cuyas estilizadas alas hasta cierto punto ya recuerdan las del Pintor de Tymbos (Belloni 1959, lám. 11,2-3) (Fig. 7.13), el de las Sirenas (Wehgartner 1991, lám. 2,1) (Fig. 7.14) y de otros pintores de pequeños lekythoi con una $\mathrm{Nike}^{8}$ (Fig. 7.15), tema muy popular a mediados del siglo $V$ a.C., cuyas obras incluso podrían ya fecharse con posterioridad al 450 a.C.

Otro tema interesante aunque generalmente poco tratado es el de la producción de

\footnotetext{
- Kurtz 1975, lám. 61,3; Wehgartner 1983, 46, data este oenochoe hacia el 470 a.C

7 "Chronique des fouilles et découvertes archéologiques en Gréce en 1954", Bulletin de Correspondance Hellénique 79, 1955, 238, fig. 13

${ }^{8}$ H.A.Cahn, IADAA Katalog 8, 1996, n²2 y Beazley, 1963, 702 s., n०24-30.
} 


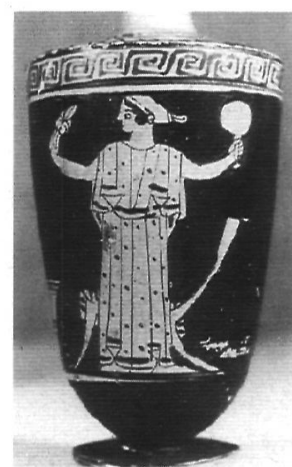

1

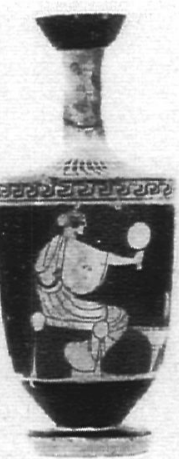

6

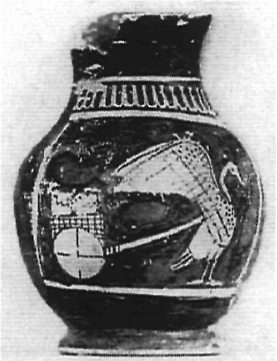

12

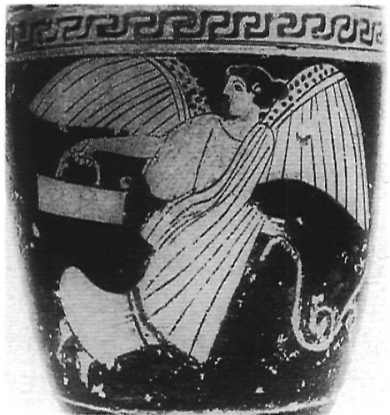

2

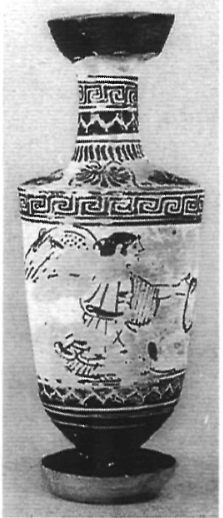

7

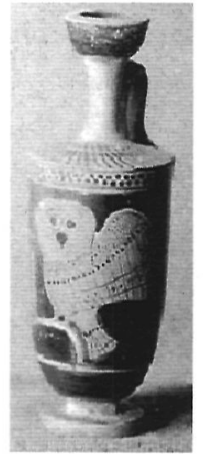

3
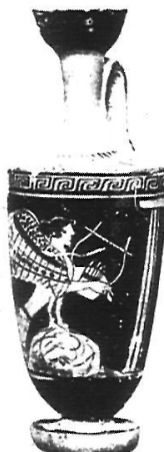

8

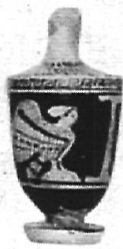

9

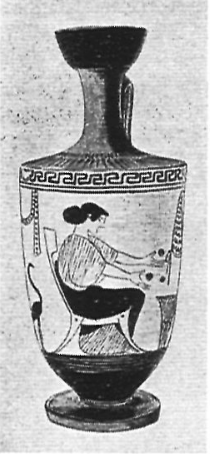

4

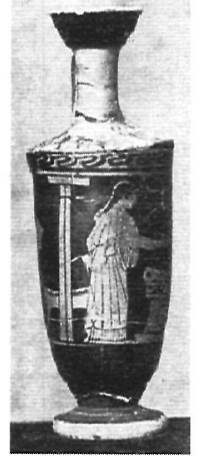

5

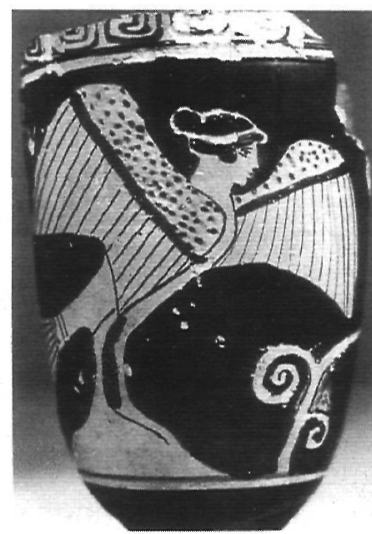

11

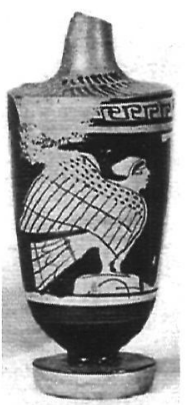

13

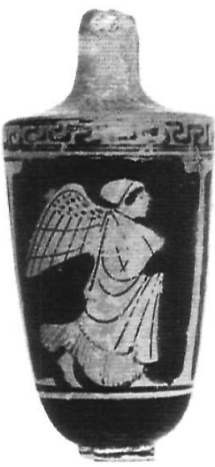

14

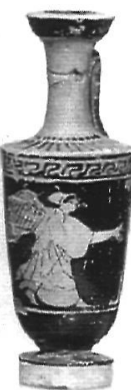

15

Figura 7: 1: Lekythos del Museo Nacional de Copenhague $n^{\circ} 137$ (según Hemelrijk, 1976); 2: Lekythos del Museo Nacional de Nápoles n 3216; 3: Lekythos con una lechuza del Museo de Frankfort; 4: Lekythos de Leipzig T 429; 5: Lekythos de Dresden ZV 2025; 6: Lekythos de Bucarest 0467; 7: Lekythos de fondo blanco de la Colección Vlasto; 8: Lekythos procedente de Cumas; 9: Lekythos de Nauplia; 10: Lekythos de Copenhague con Niké ante el altar; 11: Lekythos de Copenhague NM 167 (según Hemelrijk, 1976); 12: Oenochoe con cisne tirando de un carro del Fitzwilliam Museum, de Cambridge; 13: Lekythos del Pintor de Tymbos; 14: Lekythos del Pintor de las Sirenas; 15: Lekythos de un pintor de mediados del siglo $\mathrm{V}$ a.C.

un ceramista ático. El número de vasos conocidos atribuidos al Pintor de Ícaro actualmente rebasan el centenar, lo que permite plantear un cálculo, necesariamente teórico y aproximado, de la proporción de piezas halladas con las no conservadas o no descubiertas a fin de aproximarse a la producción real de un pintor y un taller menor, como puede considerarse este caso.
Es escasa la atención prestada a la proporción de la obra de un ceramista griego llegada hasta la actualidad (Cook, 1959, 119; id., 1972, 272 s.; Scheiber, 1983, 9; Webster, 1992, 9; Oakley, 1992, 199 s.). Para las cerámicas griegas se ha calculado en general que la proporción llegada hasta nuestros días oscila entre un optimista 3\% (Scheiber, 1983, 9) y un más realista $0,5 \%$ (Cook, 1972, 273; Webster, 
1972, 2-4 y 8, pero da el 1\% en 4). Cálculos parecidos se han hecho con las cerámicas etruscas, pues Szilagyi $(1998,685)$, basado en los cálculos anteriores, llegó a la conclusión de que se deben haber conservado unos 4.000 vasos etrusco-corintios en museos y colecciones, que supondrían entre el $0,5 \%$ y el $3 \%$ de los originariamente producidos.

En concreto, para Andokides se ha supuesto una producción de 2.500 vasos al año y una cifra parecida, de 2.000 vasos al año, se ha calculado para Euphronios con sus 10 pintores y sus alfareros colaboradores, lo que representaría que se habria conservado un 1,2 $\%$ del total de su obra (Webster, 1992, 9), cifra que consideramos optimista. Cook (1959, 119; id., 1972, 272 s.) calculó en 1957 que se habrían conservado unos 40.000 vasos áticos, concluyendo que eso suponía la existencia de unos 100 pintores activos contemporáneamente, lo que representaría al menos 400 personas, suponiendo para cada pintor un mínimo de 4 personas en su taller, mientras que Scheiber $(1983,9)$ duplica posteriormente la cifra de vasos conservados, unos 80.000 , aunque considera que representan un $3 \%$ de los originales, cifras superadas posteriormente (Rouet, 2001). Además, Cook (ibidem) analizando casos como el de Oltos, del que conocía 110 vasos en unos 25 años de producción, y el Pintor de Berlín, con 210 vasos en un periodo de unos 40 años, dedujo que la proporción conservada era de 3-4 vasos/año, mientras que de las 1300 ánforas panatenaicas supuestamente producidas cada 4 años supondrían 32.500 vasos $(25 \times 1300)$ en un siglo, de las que se conservaban el $1,3 \%$. Pero dichas cifras parecen muy optimistas y por encima de la realidad, pues cálculos posteriores más precisos de otros autores dan proporciones menores, que oscilan entre un $0,3 \%$ de Webster $(1992,3)$ y un $0,2 \%$ de Oakley $(1992,200)$, cifras que parecen más ajustados a la verdadera proporción mínima de vasos conservados (Oakley, 1992, 199).

Puede resultar también indicativo, si no más exacto, aprovechar la tradición de los precisos cálculos realizados para conocer la producción monetaria romana, como, por ejemplo, los denarios republicanos (Crawford, 1974, 640 s) o las acuñaciones de una ciudad romana provincial como Segobriga (Ripollés y Abascal, 1996, 104 s.). La proporción de monedas producidas por la ceca de esta ciudad llegada hasta la actualidad se ha calculado que no supera el $0,1 \%$ o el $0,2 \%$. Pero las monedas se conser- van mejor que las cerámicas y mucho mejor que los vasos cerámicos por ser de bronce $y$, además, han sido desde hace tiempo buscadas y conservadas por los coleccionistas. En consecuencia, parece prudente considerar que un $0,1 \%$ es una referencia teórica máxima adecuada para calcular el número de vasos de un pintor de vasos de la antigüedad llegados hasta la actualidad.

Si se parte de estos cálculos, como actualmente se conocen unas 100 piezas del Pintor de ícaro, aceptando, con evidente optimismo, como índice de conservación una proporción semejante a la de las monedas romanas para precisar su producción, se obtiene un resultado que, en cualquier caso, debería considerarse como un mínimo teórico, pues se basa sólo en los vasos hasta ahora descubiertos e identificados. Dicho resultado superaría las 50.000 y se aproximaría probablemente más a las 100.000 piezas, según se utilice el cálculo de Oakley (1992, 199 s.) o el aquí basado en la moneda romana. Cualquiera de dichas cifras resulta un dato altamente significativo sobre la eficacia y la alta productividad alcanzada por estos alfareros áticos "menores", como el "Pintor de ícaro", así como por los ceramistas átjcos en general.

\section{CONCLUSIÓN}

El análisis del pequeño lekythos RAH 824 conservado en la Real Academia de la Historia permite atribuirlo con toda seguridad al Pintor de Ícaro. Este artesano, especializado en lekythoi y en algunos otros vasos menores (Beazley, 1963, 696 s.), debió formarse en el taller del Pintor de Beldam (Haspels, 1936, 180 s.), aunque puede considerarse seguidor del Pintor de Bowdoin (Haspels, 1936, $180 \mathrm{~s}$.).

Dentro de la extensa producción de este pintor secundario relativamente prolífico ${ }^{9}$, el lekythos RAH 824 ofrece una figura de Niké en un acto de libación funeraria que, a juzgar por lo amanerado de la representación, por su pequeño tamaño y por su forma algo peculiar,

\footnotetext{
9 No se ha llegado nunca a calcular la producción artesanal de estos pintores de vasos menores. Aunque no es fácil precisar dichos cálculos, si se supone que la cantidad de vasos encontrados del Pintor de Ícaro pudiera ser el $1 \%$ de su producción, a lo largo de su vida debió haber hecho varias decenas de miles de vasos. Esta alta cifra puede sorprender, pero debe considerarse característica del sistema de producción artesanal, lo que permite comprender mejor su funcionamiento.
} 
puede considerarse un producto de la fase más avanzada de dicho pintor, si bien todavía no puede incluirse entre las obras finales de dicho artista. Por ello, este pequeño lekythos se puede fechar en el decenio 460-450 a.C., probablemente más bien hacia sus años finales.

El interés de esta obra es relativo, dada su escasa calidad y su regular estado de conservación. Sin embargo, ayuda a precisar la muy amplia producción de un artesano menor, como fue el Pintor de ícaro, en especial de sus obras más tardias, completando la nota en su día publicada por Hemelrijk (1976). Es en este punto, donde pequeños vasos como éste, a penas valorados en las colecciones, pueden ayudar a comprender el interesante proceso que supone el paso de los pintores del arcaísmo, reconocidos por su arte a pesar de su actividad artesanal como evidencia la firma de sus obras, a estos artesanos menores, cuya producción tiene el interés de poderse estimar en decenas de miles de vasos, por lo que su finalidad, más que a su goce estético y a la comunicación de mensajes heroicos, estaría dirigida a su uso meramente funcional, como debió ocurrir con el empleo funerario de este pequeño lekythos, probablemente más valorado por el perfume que contendría que por el contenedor pintado, eco decadente de una tradición decorativa ya casi perdida.

Por otra parte, este pequeño vaso griego, llegado a España en el siglo XIX como parte de la Colección Pascual de Gayangos, ofrece un relativo interés en sí mismo. Pero constituye un documento del coleccionismo de antigüedades clásicas, en concreto de vasos griegos, escasamente documentado en la España del siglo XIX. Estas actividades, propias de la nobleza culta y de la burguesía ilustrada, se desarrollaron muy poco en nuestro país en comparación con los de nuestro entorno, hecho que hay que relacionar con la situación de crisis socio-política y cultural arrastrada desde la Invasión Napoleónica y que tanta repercusión tuvo en todos los campos de la cultura, en concreto en los relacionados con la Arqueología y el Patrimonio. Por ello, el interés historiográfico de este vaso conservado en la Real Academia de la Historia complementa el que esta pequeña pieza ofrece en sí misma como mero objeto arqueológico.

Prof. Martín Almagro-Gorbea

Real Academia de la Historia

c/León 21

28014 Madrid

anticuario@rah.es

\section{BIBLIOGRAFIA}

ALMAGRO-GORBEA, M. (ed.), 1999: El Gabinete de Antigüedades de la Real Academia de la Historia, Antiquaria Hispanica 1, Madrid.

ALMAGRO-GORBEA, M. y MAIER, J., 1999: "El futuro desde el pasado: la Real Academia de la Historia y el origen y funciones del Museo Arqueológico Nacional", Boletín de la Real Academia de la Historia, 196.2, 183-208.

ALMAGRO-GORBEA, M. y MAIER, J., 2001: "Mecenas y donantes", en Tesoros de la Real Academia de la Historia (Catálogo de exposición), 191-199, Madrid.

ALMAGRO-GORBEA, M. et alii (eds.), 1999: El Disco de Teodosio, Antiquaria Hispanica 5, Madrid.

ANUARIO 2002: Anuario de la Real Academia de la Historia, Madrid.

BARTOCCINI, R. y DE AGOSTINO, A., 1961: Museo de Villa Giulia. Antiquarium e collezione dei Vasi Castellani, Milano.

BEAZLEY, J. D., 1938: Attic White Lekythoi, Oxford.

BEAZLEY, J. D., 1963: Attic Red-Figure Vase Painters ${ }^{2}$, Oxford.

BEAZLEY, J. D., 1971: Paralipomena. Additions to Attic Black-Figure Red-Vase Painters and to Red-Figure Vase Painters ${ }^{2}$, Oxford.

BEAZLEY, J. D., 1974: The Berlin Painter, London.

BELLONI, G., 1959: Corpus vasorum antiquorum. Italia, 31 Milano. Civico museo archeologico, 1, Roma.

BLINKENBERG, CHR. - FRIIS JOHANSEN, K., 1928: Corpus vasorum antiquorum - Danemark 3. Musée National (Collection des antiquités classiques), Copenhague.

BLINKENBERG, CHR. - FRIIS JOHANSEN, K., 1929: Corpus vasorum antiquorum - Danemark 1. Musée National (Collection des antiquités classiques) 1, Copenhague.

BLINKENBERG, CHR. - FRIIS JOHANSEN, K., 1931: Corpus vasorum antiquorum - Danemark 4. Musée National (Collection des antiquités classiques) 4, Copenhague.

BLONDÉ, F. y PERREOULT, J.V. (eds.), 1992: Les ateliers de potiers dans le mond grec aux époques géometrique, archaïque et classique, Actes de la Table ronde à l'École française d'Athènes 1987, Bulletin de Correspondance Hellénique, Supplément 23, Paris.

BULAS, K., 1931: Corpus vasorum antiquorum. Pologne, 1. Goluchów, Musée Czartoryski, Warszawa.

BURN, L. y GLYNN, R., 1982: Beazley Addenda. Additional references to $A B V, A R V^{2} \&$ Paralipomena, Oxford.

BUROW, J., 1986: Corpus vasorum antiquorum. Deutschland, 54. Tübingen. Antikensammlung des Archäologischen Instituts der Universität, 5, München.

CHASE, G.H. - PEASE, M.Z., 1942: Corpus Vasorum Antiquorum. USA 8. Fogg Museum and Gallatin Collections, Cambridge.

COOK, R.M., 1959: "Die Bedeutung der bemalten Keramik für den griechischen Handel", Jahrbuch des Deutschen Archäologischen Instituts, 74, 114-117.

COOK, R.M., 1972: Greek Painted Pottery², London.

COURBIN, P., 1954: "Chronique des fouilles et découvertes archéologiques en Gréce en 1953", Bulletin de Correspondance Hellénique, 78, 95-224.

CRAWFORD, M.H., 1974: Roman Republican Coinage, London.

DIMITRIU, S. y ALEXANDRESCU, P., 1965: Corpus vasorum antiquorum. Roumanie, 1. Bucarest. Institut d'archéologie. Musée national des antiquités, 1, Bucarest.

FAIRBANKS, A., 1907: Athenian Lekythoi with Outline Drawing in Matt Color on White Ground, New York.

FAIRBANKS, A., 1914: Athenian Lekythoi with Outline 
Drawing in Matt Color on White Ground, Appendix, New York.

FITA, F. y RODRIGUEZ VILLA, A., 1898: "Noticias", Boletin de la Real Academia de la Historia 32, p. 93

GABRICI, E., 1913: Cuma Monumenti Antichi publicati per cura della Reale Accademia dei Lincei 22, Roma.

GARCÍA LÓPEZ, J.C., 1903: Inventario de antigüedades y objetos de arte que posee la Real Academia de la Historia, Madrid.

GÖTTE, E., 1957: Frauengemachbilder in der Vasenmalwerei des fünften Jahrhunderts, München.

GOULAKI-VOUTIRA, A., 1992: "Nike. Klassische Zeit", Lexicon Iconographicum Mythologiae Classicae, VI, 859881.

HASPELS, C.H.E., 1936: Attic Black-Figured Lekythoi, Paris.

HAUSER, F., 1896: "Eine Sammlung von Stilproben griechischer Keramik", Jahrbuch des Deutsches Archeologischen Instituts, 11.

HEMELRIJK, J.M., 1976: "Minutiae Archaeologicae. Tow Lekythoi by the Icarus Painter in the Allard Pierson Museum", Bulletin Antieke Beschaving, 51, 93-95.

ISLER-KERÉNYI, C., 1971: “Ein Spätewerk der Berliner Malers", Antike Kunst, 14, 25-31.

KAROUZOU, S., 1962: "Scènes de palestre", Bulletin de Correspondance Hellénique, 86, 430-466.

KURTZ, D. C., 1975: Athenian White Lekythoi, Oxford.

KURTZ, D. C., 1983: The Berlin Painter, Oxford.

LAMB, W., 1936: Corpus vasorum antiquorum. Great Britain, 11. Cambridge, Fitzwilliam Museum, 2, London.

LA GENIĖRE, J. de, 1971: Corpus vasorum antiquorum. Italia, 50. Palermo. Collezione Mormino, Banco di Sicilia, 1, Roma.

MARCOS POUS, A., 1993: "Origen y desarrollo del Museo Arqueológico Nacional”, en A. Marcos Pous (ed.): De Gabinete a Museo, 21-99, Madrid.

MERCKLIN, E. von, 1935: "Neuerwerbunger der Antikenabteilung im Hamburgischen Museum für Kunst und Gewerbe", Archäologische Anzeiger, 1935.

MORA, G., 1998: Historias de Mármol. La Arqueologia Clásica española en el siglo XVIII, Madrid.
MÜLLER, W., 1925: "Erwerbungen der Antiken-Sammlungen in Deutschland", Archäologische Anzeiger, 1925, 122.

OAKLEY, H., 1992: "An Athenian Red-figure Workshop from the Time of the Peloponesian War", en F. Biondé y J.V. Perrecoult (eds.), 195-203.

PAPASPYRIDI KAROUZOU, S., 1945: "Vases from Odos Pandrosou", Journal of Hellenic Studies, 65, 38-44.

PLAOUTINE, N., 1941: Corpus vasorum antiquorum. France, 15. Palais des Beaux-Arts de la Ville de Paris (Petit Palais) Collection Dutui, Paris.

RIPOLLĖS, P.P. y ABASCAL, J.M., 1996: Las monedas de la ciudad romana de Segobriga (Saelices, Cuenca), Barcelona.

ROCA, P., 1897: "D. Pascual de Gayangos", Revista de Archivos Bibliotecas y Museos, 1, $544 \mathrm{~s}$.

ROCA, P., 1897: "D. Pascual de Gayangos", Revista de Archivos Bibliotecas y Museos, 2, $13 \mathrm{~s}$.

ROUET, Ph., 2001: Approches to the Study of Attic Vases. Beazley and Pottier, Oxford.

RUMEU DEARMAS, A., 2002: La Real Academia de la Historia, Madrid.

SCHAAL, H., 1923: Griechische Vasen aus frankfurter Sammlungen, Frankfurt.

SCHEIBLER, I., 1983: Griechische Töpferkunst. Herstellung, Handel und Gebrauch der antiker Tongefässe, München.

SZILAGYY, J.G., 1998: Ceramica etrusco-corintia figurate, 2 (Monumenti Etrusci 8), Firenze.

THOMPSON, H.A., 1948: "Excavations of Athenian Agora. Twelfth Season: 1947", Hesperia, 17, 149-196.

WEBSTER, T.B.L., 1972: Potter and Patron in Classical Athens, London.

WEHGARTNER, I., 1983: Attische weissgrundige Keramik. Maltechniken, Werkstätten, Formen, Verwendung, Keramikforschungen $V$, Mainz.

WEHGARTNER, I., 1991: Corpus vasorum antiquorum. Deutschland, 62. Berlin. Antikenmuseum ehemals Antiquarium, 8, München.

ZIMMERMANN, K., 1980: "Tätowierte Thrakerinnen auf Vasenbildern", Jahrbuch des Deutschen Archäologischen Instituts, 95, 163-196. 